\title{
Policy Considerations for Limiting Unintended Residual Plastic in Agricultural Soils
}

\author{
Marion Brodhagen ${ }^{\mathrm{a}}$, Jessica R. Goldberger ${ }^{\mathrm{b}, *}$, Douglas G. Hayes ${ }^{\mathrm{c}}$, \\ Debra Ann Inglis ${ }^{\mathrm{d}}$, Thomas L. Marsh ${ }^{\mathrm{e}}$, and Carol Miles ${ }^{\mathrm{f}}$
}

a Department of Biology, Western Washington University, Bellingham, WA, USA

${ }^{\mathrm{b}}$ Department of Crop and Soil Sciences, Washington State University, Pullman, WA, USA

${ }^{c}$ Department of Biosystems Engineering and Soil Science, University of Tennessee, Knoxville, TN, USA

d Department of Plant Pathology, Washington State University Northwestern Washington Research \& Extension Center, Mount Vernon, WA, USA

e School of Economic Sciences, Washington State University, Pullman, WA, USA

${ }^{\mathrm{f}}$ Department of Horticulture, Washington State University Northwestern Washington Research \& Extension Center, Mount Vernon, WA, USA

* Corresponding author's e-mail address: jgoldberger@wsu.edu.

Abstract: Growing crops under high-intensity agriculture entails the use of numerous plastic products, especially polyethylene plastic films used as crop mulches. As a result, some of the world's most productive agricultural soils are now being affected by plastic pollution, seriously threatening soil health and food security. Plastic film mulches designed to biodegrade in soil provide an appealing alternative to polyethylene films. What may be surprising, however, is that biodegradable plastic films do not necessarily represent a long-term solution to the problem of contaminating soil with plastic residues. Transformative science and policies are needed to mitigate uncertainty of biodegradable plastic residue accumulation in agricultural soils.

Keywords: Plastic Mulches, Biodegradation, Soil Health, Plastic Pollution, Policy 


\section{Policy Considerations for Limiting Unintended Residual Plastic in Agricultural Soils}

\section{Introduction}

To meet the world's increasing demand for food, and global development goals for food security, modern agriculture relies heavily on plastic products, especially plastic films, which are used for applications including crop mulches, greenhouse coverings, labels, and silage wraps. The global market for agricultural plastic films, worth more than U.S. \$5.8 billion (2012), is projected to grow 7.6\% per year through 2019 (Transparency Market Research, 2013).

Plastic films used as crop mulches are composed typically of low-density polyethylene, or LDPE (Lamont, 1993), and play an essential role in fruit and vegetable production. Short-term benefits provided to growers by plastic film mulches include fewer weed problems, reduced soil water evaporation, earlier and higher yields, and higher-quality produce (Lamont, 1993). Because of their tremendous utility in agriculture, the use of plastic film mulches is increasing worldwide, while simultaneously exposing some of the world's most productive and valuable soil resources to plastic residue. The extent to which agricultural soils are mulched with plastic film on a global scale is uncertain and represents a critically important information gap that remains to be filled. Nonetheless, in China in 2011, nearly 20 million hectares were reported to be mulched, with use projected to grow $7.1 \%$ or more annually (Liu et al., 2014).

The expanding use of LDPE plastic films for crop mulching can be associated with significant costs to farmers and broader society. Once degraded via weathering, plastic film mulch fragments often are incorporated or left behind in agricultural soils, risking pollution of the broader terrestrial environment and, via run-off, the marine environment (Jambeck et al., 2015). Additionally, removal of plastic film mulch from the field is labor-intensive, disposal is costly, and recycling and reuse are difficult because soil particles often adhere tightly and plastic film mulch easily tears into small pieces due to weathering. Socially undesirable disposal methods include burning or tilling used plastic film mulch directly into the soil. Because open burning of agricultural plastics threatens air quality and public health, regulations banning this activity have been enacted in various parts of the world. And, where plastic film mulches have been used and tilled into fields repeatedly in China, plastic residue ranges from $72 \mathrm{~kg} / \mathrm{ha}$ to 260 $\mathrm{kg} / \mathrm{ha}$ (Liu et al., 2014). Plant growth is inhibited at these levels, and the accumulated plastic residue may affect soil moisture, nutrient transport, and secondary salinization (Liu et al., 2014). 
A recent and comprehensive review by Steinmetz et al. (2016) catalogs benefits (such as those listed above), detriments (e.g., increased runoff of sediments and pesticides), and variability of the agroecosystem impacts of LDPE mulch films. However, knowledge about the long-term effects of plastic residues in agroecosystems is sparse (Rillig, 2012; Steinmetz et al., 2016), as are policy solutions, signifying a poorly recognized environmental problem.

Plastic film mulches designed to biodegrade in soil provide an appealing alternative to LDPE crop mulches. Several products claiming biodegradability are now on the market. There is great interest in these products among specialty crop growers, agricultural extension agents, agricultural input suppliers, and other stakeholders (Goldberger et al., 2015). Yet, even more than with LDPE mulch films, the social and environmental costs associated with long-term use of biodegradable materials are unknown. Specifically, it is unclear how much residue might remain in soils from biodegradable plastic film mulches, and what effects such residues might have on soil ecosystems.

The major reason why in-soil breakdown cannot be predicted is that many plastic mulch products are certified to meet the standards of biodegradation only under the conditions of industrial composting. While biodegradation in soil could be inferred from the products' labels, compostability cannot necessarily be extrapolated to biodegradability under the field soil conditions of commercial agriculture. A standard that ensures biodegradation of plastic film in soil has yet to be established, although significant efforts are in progress. From a policy perspective, developing a new standard would provide a credible mechanism to test products with uncertain environmental outcomes, thereby enhancing protection of terrestrial and downstream marine environments from the risks posed by plastic film mulch residues that may not fully biodegrade.

\section{Revisiting Current Standards}

Nearly complete biodegradation (microbial conversion into carbon dioxide and/or methane and water) of the polymers typically used to manufacture biodegradable plastic film mulches can be achieved under industrial composting conditions. In part, the conversion relies on high temperatures not typically found in agricultural soils. Existing standards for industrial composting of biodegradable materials such as ASTM D6400 (ASTM International, 2012) employ a test method that inherently assumes soil microbial respiration to produce $44 \mathrm{~g} \mathrm{CO}_{2}$ for 
every $12 \mathrm{~g}$ C consumed. ASTM D6400 requires that $\geq 90 \%$ of theoretical $\mathrm{CO}_{2}$ evolution be achieved within 180 days under controlled laboratory conditions (nutrients, $\mathrm{pH}$, soil moisture, temperature) for plastics or for single organic constituents that comprise $>1 \%$ of the product. ASTM D6400 permits persistence of fragments that are $\leq 2 \mathrm{~mm}$ (classified as microplastics). Thus compost, if used as a soil amendment, may be a source of residual microplastic.

The fate and transport of microplastics is largely unstudied in soil ecosystems (Rillig, 2012). ASTM D6400 and other compostability standards do not address biodegradation in soil. It is important to note that non-degraded plastic fragments and microplastics that accumulate in soil are not necessarily biologically inert. In marine systems, microplastics have been shown to adsorb hydrophobic toxicants, which can be released and absorbed into living cells upon ingestion (Bergmann et al. 2015). Biodegradable plastic film mulches also are typically hydrophobic, and have the potential ability to adsorb certain pesticides or other compounds commonly used in crop production.

Many fruit and vegetables grown in mulched cropping systems are annual plants and consequently most biodegradable plastic film mulches are designed for single-season, but repeated use. Soil-biodegradable plastic film mulches could be applied and tilled into the same field each succeeding crop year. Even with a $90 \%$ biodegradation benchmark (as per ASTM D6400 and other compostability standards), repeated soil incorporation of biodegradable plastic film mulches could result in significant, unsustainable soil accumulation of plastic film fragments and microplastics, affecting agricultural ecosystems in as-yet uncertain and undefined ways. The effects of accumulated plastic mulch fragments on soil-dwelling microflora and fauna, or on soil physical and chemical properties, are not addressed by the compostability standards currently used to certify them. Thus, the environmental repercussions of plastic accumulation in soils are largely unknown, in contrast to the increasing documentation of the harmful impacts of plastic waste to marine environments (Kershaw, 2015). Given the known harm plastics cause in the marine ecosystem, we are advocating rigorous examination of the long-term effects of plastic on agroecosystems before a global-scale adoption of plastic intended for incorporation into soils.

\section{Developing a New Standard}

An opportunity exists to develop a new standard for biodegradation of plastic film mulch in soil that takes into account the unique conditions encountered in terrestrial systems, and 
accomplishes the long-term, ecosystem-level monitoring not achieved by compostability standards. Developing a new standard could clarify the uncertainty regarding soil pollution resulting from long-term and repeated mulch use, providing the necessary knowledge to guide agricultural practices that could mitigate such uncertainty. Preemptive action on this front by creating a standard that subscribes to a relevant risk assessment could help to avert a potential agricultural soil crisis similar to the one facing the marine environment.

\subsection{In situ testing}

While laboratory tests are convenient because they are easily standardized, passing a requisite laboratory test does not guarantee biodegradation across a diversity of soil ecosystems. In agricultural settings, soil and environmental conditions vary broadly across sites and seasons. Weathering of mulch (degradation by sunlight, temperature extremes, water, wind, etc. prior to removal or tillage into the soil), directly affects the rate of breakdown. An in-soil biodegradation standard needs to include a reasonable testing range of soil moisture and temperature, crop and soil types, and associated microbial communities, and the testing should be carried out under selected field conditions that simulate typical farming practices and biodegradable plastic film mulch weathering. Because biodegradable plastic film mulches are likely to be re-applied and tilled into the soil on an annual or semi-annual basis, long-term assessments about the number, size, character, and fate and transport of the fragments, along with effects on the soil ecosystem, need to encompass repeated mulch laying and tilling-in over multiple years. Accurately characterizing biodegradation of plastics in the chemically complex environment of soil, admittedly, is difficult. The scope and timeframe of such long-term studies might fall under the purview of federal agencies, industry, academia, and/or other organizations that support research on agricultural and environmental safety.

\subsection{Biodegradable film mulch labels}

Plastic film mulch labels should not conflate "compostable" and "biodegradable." It is not unusual to see the term "biodegradable" used solely, without "compostable" also listed on product labels, implying in situ soil degradation-misleading information that can lead to inappropriate soil incorporation of certain products. As an example, two commercially available biodegradable plastic film mulches that degrade under composting conditions were introduced 
into field soil inside nylon mesh bags at three climatically distinct agricultural locations in the U.S. Although a non-plastic, cellulosic control mulch left no visible remnants at any of the three locations, $>40 \%$ of the surface area of the two biodegradable plastic film mulches was visibly detectable after two years of soil burial at two of the locations (Li et al., 2014). Labels need to be clear as to the environmental conditions under which products are biodegradable, and they need to provide supportive evidence for claims of biodegradability. Because the types and proportions of polymeric constituents and additives in biodegradable plastic film mulches frequently change as manufacturers optimize products and adjust to market forces, labels also should accurately reflect current product formulations.

\subsection{Continual review}

We live in a world of standards that promote societal and industrial values such as efficiency, precision, consistency, product quality, trade, and safety. Standards are the "recipes by which we create realities" (Busch, 2011). Although developing, implementing, and changing standards can be contentious, costly, and time-consuming, standards become obsolete when they do not reflect authentic circumstances (Busch, 2011). ASTM D6400 and other standards that relate to the use of biodegradable plastic films and the environment typically undergo periodic revision as scientific knowledge expands. Updated standards should incorporate new knowledge on rates of accumulation and environmental repercussions of plastic residues in food production systems. Crucial to these revisions will be reliable data collected periodically on the extent to which agricultural soils are mulched with both LDPE and biodegradable plastic film mulches on a global scale.

\section{Transforming Science and Policy}

Environmental testing, such as embedded in the in-soil biodegradation standard that we advocate above, and subsequent prevention of environmental pollution require effort and resources. Upon whom should the burden of responsibility lie? Traditional economic instruments (e.g., subsidies, taxes, fees, and standards) and legislation may be implemented at different points of the supply chain for the purpose of improving deployment and disposal practices and reducing pollution (Tietenberg and Lewis, 2014). Although downstream interventions at the point of disposal are essential, they have not solved the world's plastic pollution problem. A soil 
biodegradation standard would represent a voluntary mechanism placed upstream at the point of manufacture, and when coupled with advances in scientific knowledge, is likely one of the most practical policy tools to limit plastic contamination of the soil as well as the downstream marine environment (Kershaw, 2015).

Beyond manufacturing standards, other progressive policy responses and mixed solutions are being tested. Finland, Norway, and Sweden have turned to an extended responsibility system using a mix of instruments whereby upstream manufacturers of plastic products are required to finance downstream recycling and waste disposal (Hennlock et al., 2014). In this system, upstream manufacturers as well as downstream consumers pay taxes and fees, with the goal of reducing consumption and increasing recycling.

The U.S. takes a precautionary stance to managing uncertainty by placing a burden of evidence on the plastic film manufacturer itself. A manufacturer must provide reliable scientific evidence to support its labeling (FTC, 2012), which incentivizes industry to seek innovative solutions. The Federal Trade Commission (FTC) prohibits deceptive acts and practices in commerce, including implications that a product or package is degradable, biodegradable, or compostable (FTC, 2012). States may also impose additional regulations and policies. The misuse of the term 'biodegradable' on plastic products by marketing companies led California to enact a law to further protect itself against increased plastic litter (State of California, 2015). In the longer run, opportunities exist to harmonize codes and standards for biodegradable plastic films at international, federal, state and/or provincial levels, and can serve to streamline labeling and guide technological progress. To be practical, such codes would require various means of cost effective monitoring and enforcement.

Efficient solutions that reduce social costs from pollution and also protect the environment require not only sound science, but also an effective policy process under uncertainty (Polasky et al., 2011). Policy solutions must strike a balance so as not to be so rigid that they stifle future innovations in biodegradable plastic film mulches, nor so laissez-faire that they lead to pollution of the world's most productive soils with plastic residue. To ensure an operational regulatory landscape, transformative science is needed to support appropriate agricultural uses, manufacturing standards, and policy instruments. More accurate scientific information and effective standards governing in situ soil biodegradation are necessary to 
balance the commercial viability of biodegradable plastic film mulches in agriculture with environmental safety and the social good.

\section{Acknowledgements}

The authors acknowledge USDA-Specialty Crop Research Initiative (SCRI) grant project Biodegradable Mulches for Specialty Crops Produced Under Protective Covers (Ref. No: 200902484) and USDA-SCRI grant project Performance and Adoptability of Biodegradable Plastic Mulch for Sustainable Specialty Crop Production (Ref. No. 2014-51181-22382). The authors thank R.J. Cook, J. Gulledge, D. Jackson-Smith, R. Koenig, and R. Narayan for critically reviewing an earlier draft of this opinion paper.

\section{References}

ASTM International. 2012. Designation: D6400-12: Standard Specification for Labeling of Plastics Designed to be Aerobically Composted in Municipal or Industrial Facilities. ASTM International, West Conshohocken, PA.

Bergmann, M., Gutow, L., Klages, M (Eds.). 2015. Marine Anthropogenic Litter. Springer

International Publishing AG, Cham, Switzerland. doi: http://dx.doi.org/10.1007/978-3-31916510-3.

Busch, L. 2011. Standards: Recipes for Reality. MIT Press, Cambridge, MA.

Federal Trade Commission (FTC). 2012. FTC 16 CFR Part 260: Guides for the Use of Environmental Marketing Claims; Final Rule. Federal Register. Vol. 77, No. 197. https://www.ftc.gov/sites/default/files/documents/federal_register_notices/guides-useenvironmental-marketing-claims-green-guides/greenguidesfrn.pdf.

Goldberger, J.R., Jones, R.E., Miles, C.A., Wallace, R.W., Inglis, D.A. 2015. Barriers and bridges to the adoption of biodegradable plastic mulches for U.S. specialty crop production. Renew. Agr. Food. Syst. 30(2), 143-153. doi: http://dx.doi.org/ $10.1017 /$ S1742170513000276.

Hennlock, M., zu Castell-Rüdenhausen, M., Wahlström, M., Kjær, B., Milios, L., Vea, E., Watson, D., Hanssen, O.J., Fråne, A., Stenmarck, A., Tekie, H. 2014. Economic Policy 
Instruments for Plastic Waste-A Review with Nordic Perspectives. Nordic Council of Ministers, Copenhagen.

Jambeck, J.R., Geyer, R., Wilcox, C., Siegler, T.R., Perryman, M., Andrady, A., Narayan, R., Lavender Law, K. 2015. Plastic waste inputs from land into the ocean. Science 347, 768771. doi: http://dx.doi.org/10.1126/science.1260352.

Kershaw, P.J. (Ed.). 2015. Sources, Fate and Effects of Microplastics in the Marine Environment: A Global Assessment. Rep. Stud. GESAMP No. 90. IMO/FAO/UNESCOIOC/UNIDO/WMO/IAEA/UN/UNEP/UNDP Joint Group of Experts on the Scientific Aspects of Marine Environmental Protection. http://www.gesamp.org/publications/publicationdisplaypages/reports-and-studies-no.-90

Lamont, W.J. 1993. Plastic mulches for the production of vegetable crops. HortTechnol. 3, 3539.

Li, C. Moore-Kucera, J., Miles, C., Leonas, K., Lee, J., Corbin, A., Inglis, D. 2014. Degradation of potentially biodegradable plastic mulch films at three diverse U.S. locations. Agroecol. Sustain. Food Syst. 38, 861-889. doi: http://dx.doi.org/10.1080/21683565.2014.884515.

Liu, E.K., He, W.Q., Yan, C.R. 2014. 'White revolution' to 'white pollution'-agricultural plastic film mulch in China. Environ. Res. Lett. 9, 091001. doi: http://dx.doi.org/10.1088/1748-9326/9/9/091001.

Polasky, S., S. Carpenter, C. Folke, and B. Keeler. 2011. Decision-making under great uncertainty: environmental management in an era of global change. Trends Ecol. Evol. 26(8), $398-404$.

Rillig, M.C. 2012. Microplastic in terrestrial ecosystems and the soil? Environ. Sci. Technol. 46, 6453-6454. doi: http://dx.doi.org/10.1021/es302011r.

State of California. 2015. Public Resources Code Section 42355-42358.5. http://www.leginfo.ca.gov/cgi-bin/displaycode?section=prc\&group=42001$43000 \&$ file $=42355-42358.5$ (11.15.15).

Steinmetz, Z., Wollmann, C., Schaefer, M., Buchmann, C., David, J., Tröger, J., Muñoz, K., Frör, O., Schaumann, G.E. 2016. Plastic mulching in agriculture. Trading short-term agronomic benefits for long-term soil degradation? Sci. Total Environ. 550, 690-705. doi: http://dx.doi.org/10.1016/j.scitotenv.2016.01.153 
Tietenberg, T., Lewis, L. 2014. Environmental and Natural Resource Economics, tenth ed. Routledge, London.

Transparency Market Research. 2013. Agricultural films (LDPE, LLDPE, HDPE, EVA/EBA, reclaims and others) market for greenhouse, mulching and silage applications - Global industry analysis, size, share, growth, trends and forecast, 2013-2019. http://www.transparencymarketresearch.com/pressrelease/agricultural-film.html. 